Article

\title{
Energy Absorption and Limit Velocity of Epoxy Composites Incorporated with Fique Fabric as Ballistic Armor-A Brief Report
}

\author{
Michelle Souza Oliveira ${ }^{1}\left(\mathbb{D}\right.$, Fernanda Santos da Luz ${ }^{1, *(\mathbb{D}}$, Henry Alonso Colorado Lopera ${ }^{2}$, \\ Lucio Fabio Cassiano Nascimento ${ }^{1}$, Fabio da Costa Garcia Filho ${ }^{1}$ (D) and Sergio Neves Monteiro ${ }^{1}$ (D) \\ 1 Department of Materials Science, Military Institute of Engineering-IME, Praça General Tibúrcio 80, Urca, \\ Rio de Janeiro 22290-270, Brazil; oliveirasmichelle@ime.eb.br (M.S.O.); lucio@ime.eb.br (L.F.C.N.); \\ fabiogarciafilho@gmail.com (F.d.C.G.F.); snevesmonteiro@gmail.com (S.N.M.) \\ 2 CCComposites Laboratory, Universidad de Antioquia-UdeA, Calle $70 \mathrm{n}^{\circ}$ 52-21, Medellin 050010, Colombia; \\ henry.colorado@udea.udea.edu.co \\ * Correspondence: fsl.santos@gmail.com
}

Citation: Oliveira, M.S.; Luz, F.S.d. Lopera, H.A.C.; Nascimento, L.F.C.; Garcia Filho, F.d.C.; Monteiro, S.N. Energy Absorption and Limit Velocity of Epoxy Composites Incorporated with Fique Fabric as Ballistic Armor-A Brief Report. Polymers 2021, 13, 2727 https://doi.org/10.3390/ polym13162727

Academic Editor: Francisco Javier Espinach Orús

Received: 18 July 2021

Accepted: 12 August 2021

Published: 15 August 2021

Publisher's Note: MDPI stays neutral with regard to jurisdictional claims in published maps and institutional affiliations.

Copyright: (c) 2021 by the authors. Licensee MDPI, Basel, Switzerland. This article is an open access article distributed under the terms and conditions of the Creative Commons Attribution (CC BY) license (https:// creativecommons.org/licenses/by/ $4.0 /)$

\begin{abstract}
Polymer composites reinforced with natural fabric have recently been investigated as possible ballistic armor for personal protection against different levels of ammunition. In particular, fabric made of fique fibers, which is extracted from the leaves of the Furcraea andina, was applied as reinforcement for polymer composites used in a multilayered armor system (MAS). The superior performance of the fique fabric composites as a second MAS layer motivated this brief report on the determination of the absorbed energy and capability to limit velocity in the stand-alone ballistic tests. The single plates of epoxy composites, which were reinforced with up to $50 \mathrm{vol} \%$ of fique fabric, were ballistic tested as targets against $7.62 \mathrm{~mm}$ high-speed, $\sim 840 \mathrm{~m} / \mathrm{s}$, impact ammunition for the first time. The results were statistically analyzed by the Weibull method and ANOVA. The absorbed energies of the 200-219 J and limit velocities of 202-211 m/s were found statistically similar to the epoxy composites reinforced with the fique fabric from 15 to $50 \mathrm{vol} \%$. Predominantly, these findings are better than those reported for the plain epoxy and aramid fabric (Kevlar ${ }^{\mathrm{TM}}$ ) used as stand-alone plates with the same thickness. Macrocracks in the 15 and $30 \mathrm{vol} \%$ fique fabric composites compromise their application as armor plates. The delamination rupture mechanism was revealed by scanning electron microscopy. By contrast, the integrity was maintained in the 40 and $50 \mathrm{vol} \%$ composites, ensuring superior ballistic protection compared to the use of Kevlar ${ }^{\mathrm{TM}}$.
\end{abstract}

Keywords: fique fabric; epoxy composite; ballistic test; limit velocity; energy absorption; ballistic armor

\section{Introduction}

Synthetic laminates made of ultra-high-molecular-weight polyethylene (UHMWPE), under the trademarks of Dyneema ${ }^{\mathrm{TM}}$ and Spectra ${ }^{\mathrm{TM}}$, as well as aramid fiber, supplied as Kevlar $^{\mathrm{TM}}$ and Twaron ${ }^{\mathrm{TM}}$, have been the most common materials used worldwide for bulletproof vests [1-3]. Past decades witnessed a surge in research on the possible substitution of polymer composites reinforced with natural fiber/fabric for synthetic laminates [4-7]. In addition to sustainable issues, natural fiber/fabric composites possess a comparable capacity to dissipate the ballistic energy with cost-effective advantages [8-15]. The ballistic tests in all of these previous studies, as well as in the present investigation, were conducted according to the NIJ standards [16].

Among the numerous natural fabrics that have been investigated as reinforcement for polymer composites in personal ballistic armor, the fique fabric displayed superior performance as a second layer in a multilayered armor system's (MAS's) front ceramic plate [17,18]. In addition, previous studies have evaluated the mechanical properties of the fique fabric epoxy composites by means of impact [19] and tensile tests [20]. The results of these studies have shown that the fique fabric acts as reinforcement, since the incorporation of fique fabric up to $60 \mathrm{vol} \%$ increases the value of the tensile strength of the composites by more than 
twice [20]. Likewise, the epoxy composites with up to $40 \mathrm{vol} \%$ of fique fabric exhibited an increase of 2.3 times in the amount of impact energy absorbed in the Izod tests [19].

However, the ballistic performance of the fique fabric composite associated with the standard backface signature (BFS) [16] was, on average, not only better than other natural fabrics, but was also better than using $\operatorname{Kevlar}^{\mathrm{TM}}$ as an MAS second layer with the same thickness [17,18]. Pereira et al. [17] found that polyester composites reinforced with 10, 20 and $30 \mathrm{vol} \%$ fique fabric displayed a BFS of $16-20 \mathrm{~mm}$, which is much less than the limit value of $44 \mathrm{~mm}$ imposed by the standard as a lethal trauma [16]. Moreover, these BFS values are better than the average $23 \mathrm{~mm}$ which has been reported for the MAS with $\operatorname{Kevlar}^{\mathrm{TM}}$ as the second layer with the same thickness [11]. The mechanisms of rupture of the polyester matrix, as well as the fabric/matrix delamination, and the individual rupture of fique fibers, were revealed by scanning electron microscopy (SEM) [17]. Oliveira et al. [18] reported a BFS of 20-23 mm for the front ceramic MASs with epoxy composites reinforced with 15, 30, 40 and $50 \mathrm{vol} \%$ of fique fabric as the second layer. The SEM analysis showed evidence of fabric yarn pullout and fique fiber stretching, as well as fiber ruptures and matrix cracks.

Regarding the ballistic tests, in addition to BFS determination in the MAS target, two important ballistic parameters can be obtained in stand-alone targets. These are the absorbed impact energy and the limit velocity. Different than the MAS target, in standalone targets the target is only the composite plate without the front ceramic [16]. Owing to the high impact velocity of the $7.62 \mathrm{~mm}$ projectile, the stand-alone plate is perforated. The residual velocity of the projectile coming out of the plate allows the impact energy absorbed by the composite to be measured. This does not only provide the amount of energy that can be dissipated by the composite alone, but also provides the highest projectile velocity in which the target plate is not perforated; this is known as the limit velocity. In terms of ballistic protection, the limit velocity might indicate the level of ammunition against which the plate could still be used alone as an effective armor.

This brief report complements previous BFS results from the ballistic tests of fique fabric reinforced epoxy composites as an MAS second layer [18]. For the first time, the absorbed energy and limit velocity in stand-alone targets against the threat of $7.62 \mathrm{~mm}$ ammunition have been measured.

\section{Materials and Methods}

\subsection{Materials}

The fique fabric, illustrated in Figure 1, is plain woven with an areal density of $859 \mathrm{~g} / \mathrm{cm}^{2}$ in accordance with the NBR 10591/2008 standards [21]. Fique fibers were extracted from the mountain plant Furcraea andina, which is native of the Andean regions of Colombia, Ecuador and Peru. In Colombia, fique fibers are commonly available in applications such as textiles for clothes, and fabrics for agricultural products, including sackcloth. The possibility of using fique fabric as reinforcement for polymer composites was reported by Monteiro et al. [22], which motivated its applications as ballistic armor [17,18] As seen in all previous works, including the present brief report, the fique fabric (Figure 1) was brought from Medellin, Colombia, by one of the authors (H.A.C.L.). 


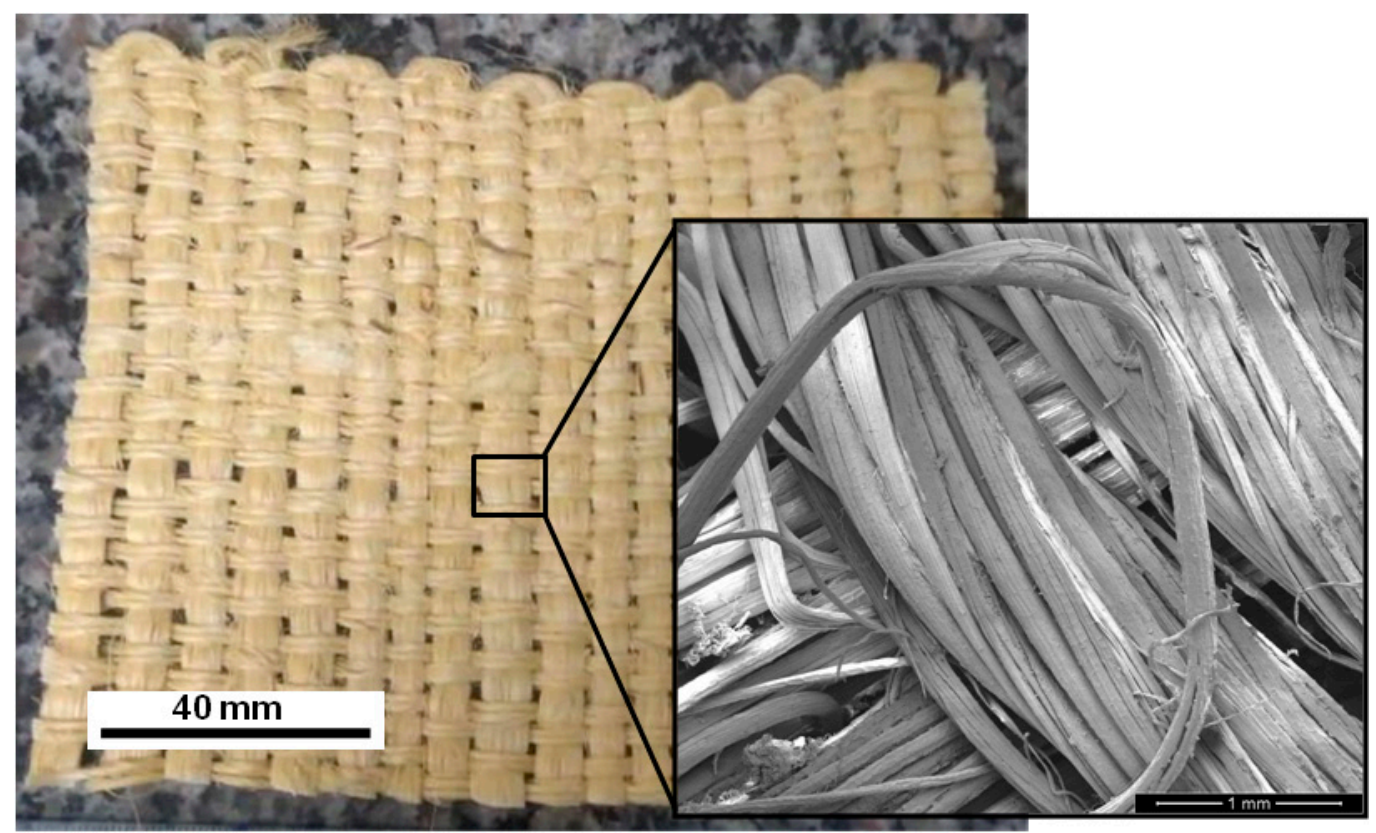

Figure 1. Plain woven fique fabric and microscopic inset of weaved fibers (adapted from [18]).

As composite matrix, the commercial epoxy resin diglycidyl ether of the bisphenol-A (DGEBA) was used in a stoichiometric mixture which was hardened with a triethylenetetramine (TETA) catalyst of 13 parts per 100 of resin. Both DGEBA ( 100\% purity) and TETA ( $\geq 96 \%$ purity) were produced by Dow Chemical and supplied by Epoxyfiber, Rio de Janeiro, Brazil.

\subsection{Composite Fabrication}

The as-received fique fabric (Figure 1) was cut into $120 \times 150 \mathrm{~mm}$ pieces that were cleaned in running water to remove impurities, and then dried in a stove at $60{ }^{\circ} \mathrm{C}$ for $24 \mathrm{~h}$. The average density of the dried fabric was then measured by a gas pycnometer, Ultrapycnometer 1000 (Quantachrome Instruments, Boynton Beach, FL, USA), and found to be $1.53 \mathrm{~g} / \mathrm{cm}^{3}$, whereas that of the DGEBA/TETA epoxy was reported as $1.11 \mathrm{~g} / \mathrm{cm}^{3}$ [22]

Composite plates with $15,30,40$ and $50 \mathrm{vol} \%$ of fique fabric were produced in a steel mold with an internal volume of $180 \mathrm{~cm}^{3}\left(150 \times 120 \times 10 \mathrm{~mm}^{3}\right)$ by hand lay-up process. Still fluid DGEBA/TETA epoxy was poured in the mold, filling up the empty space with the precise amount corresponding to the desired volume fractions which were calculated by the fabric and resin densities. Then, the mold was closed, and the composite plate was cured under a 5-tonne load applied by a SKAY hydraulic press, São Paulo, Brazil. Table 1 presents the nomenclature used for the investigated composites.

Table 1. Nomenclature adopted for the composites.

\begin{tabular}{cl}
\hline Nomenclature & \multicolumn{1}{c}{ Material } \\
\hline EC15BF & Epoxy composite with $15 \mathrm{vol} \%$ fique fabric \\
EC30FF & Epoxy composite with $30 \mathrm{vol} \%$ fique fabric \\
EC40BF & Epoxy composite with $40 \mathrm{vol} \%$ fique fabric \\
EC50BF & Epoxy composite with 50 vol\% fique fabric \\
\hline
\end{tabular}

\subsection{Stand-Alone Ballistic Tests}

Stand-alone ballistic tests were conducted at the Army Assessment Center (CAEx) in Rio de Janeiro, Brazil, using level III $7.62 \times 51 \mathrm{~mm}$ caliber ammunition with $9.7 \mathrm{~g}$ of mass [16]. 
Figure 2 schematically illustrates the CAEx shooting line. The $7.62 \mathrm{~mm}$ projectile was shot from a gun barrel with an initial velocity of $838 \pm 15 \mathrm{~m} / \mathrm{s}$ and hit the standalone composite plate, positioned $15 \mathrm{~mm}$ from the gun, with a perpendicular $\left(90^{\circ}\right.$ angle) trajectory. The optical barrier with the HPI B471 chronograph and model Weibel SL-520P Doppler radar measured both the impact velocity $\left(v_{i}\right)$ against the target plate and the residual velocity $\left(v_{r}\right)$ of the projectile leaving the plate after perforation. An actual image (radar spectrum) recording for the projectile velocity (shown in Figure 2b) indicated that the perforation time occurred at around $20 \mathrm{~ms}$ for the ballistic tests.

(a)

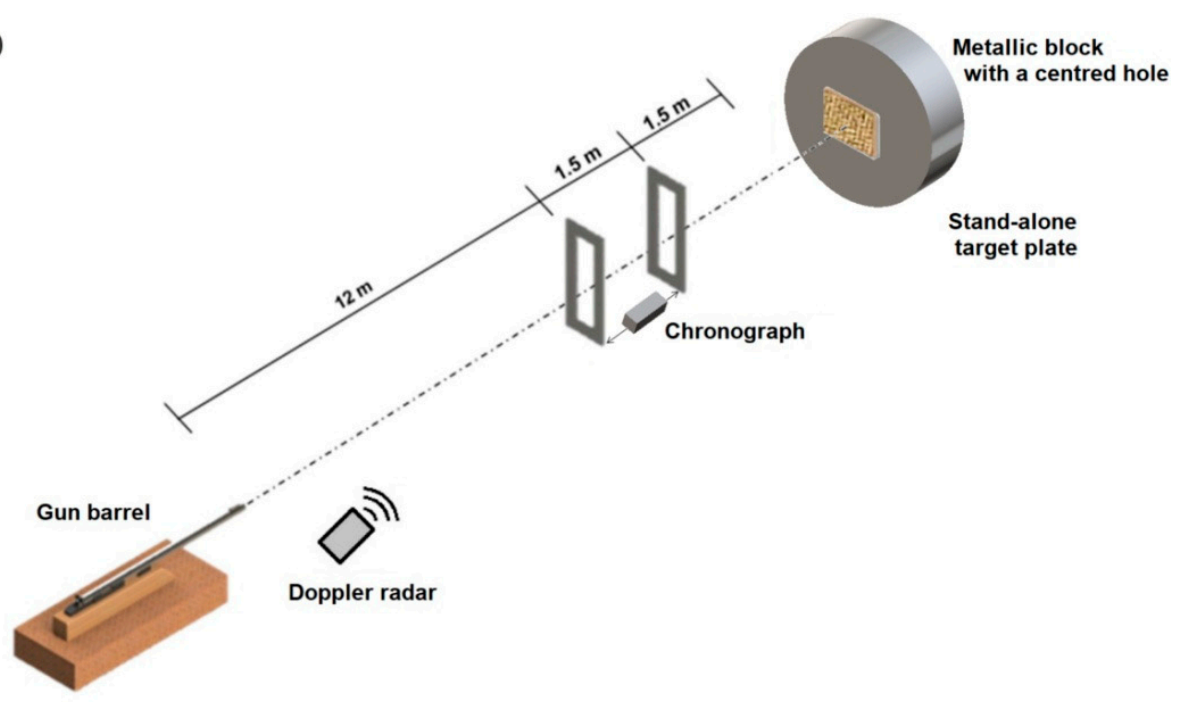

(b)

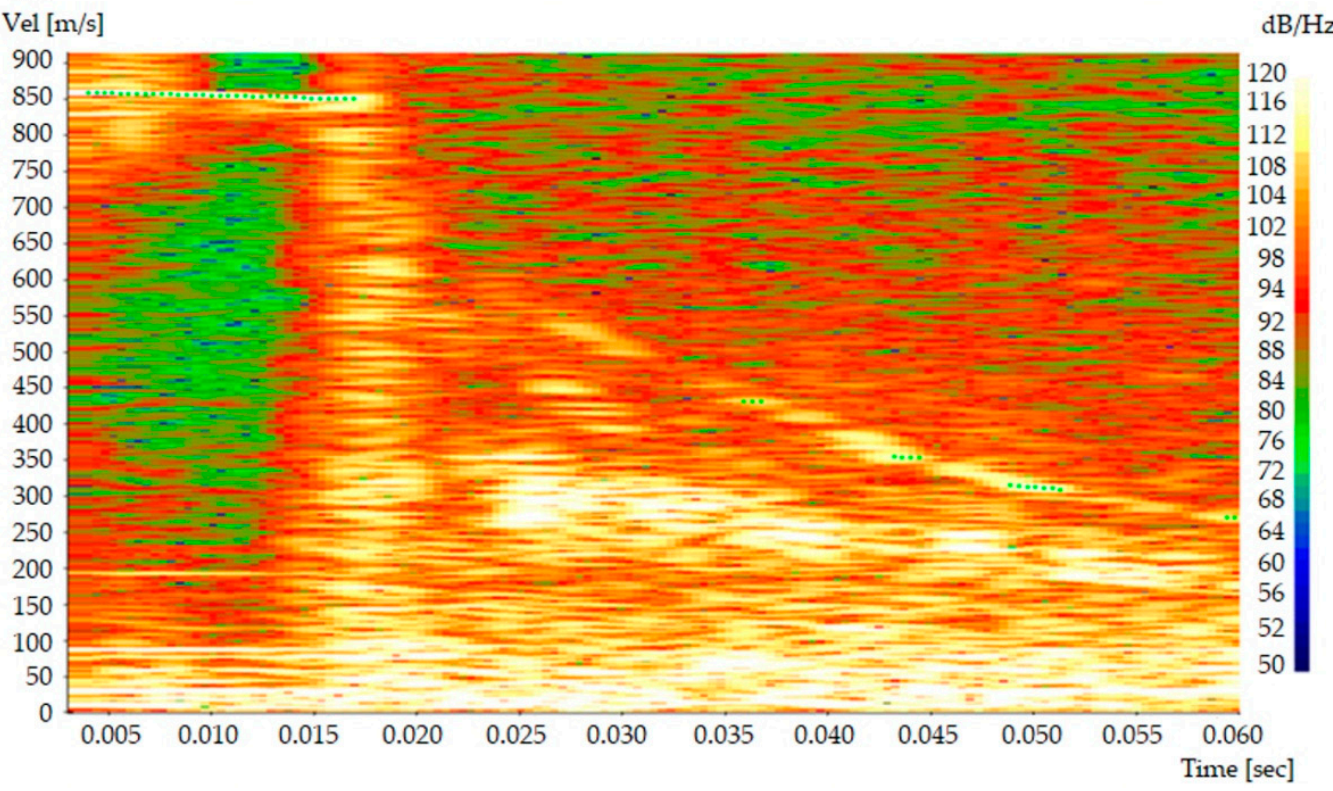

Figure 2. (a) Schematic illustration of the CAEx shooting line for stand-alone ballistic test with $7.62 \mathrm{~mm}$ ammunition; (b) Actual computer-recorded image (radar spectrum) of projectile velocity variation with time also presented.

\subsection{Ballistic Parameters}

The absorbed ballistic impact energy $\left(E_{a b s}\right)$ of the stand-alone target plate schematically illustrated in Figure 2 is given by [9]:

$$
E_{a b s}=\frac{m_{p} \cdot\left(v_{i}{ }^{2}-v_{r}{ }^{2}\right)}{2}
$$


where $m_{p}$ is the mass, $v_{i}$ and $v_{r}$ are the impact and residual velocities, respectively. The values of $v_{i}$ and $v_{r}$ were calculated for each shot using the program WinDopp ${ }^{\circledR}$, Weibel. The data acquisition by the radar generates a frequency spectrum in the obtained time (Figure 2b), which correlates intensity with velocity by Fast Fourier Transform (FFT) to obtain the velocity curve fitting shown in Figure 3. In this figure, it should be noticed that at $\sim 840 \mathrm{~m} / \mathrm{s}$ there is an abrupt decrease, which indicates the velocity $\left(v_{i}\right)$ at the instant of impact. The velocity decrease to $\sim 815 \mathrm{~m} / \mathrm{s}$ in Figure 3 illustrates the way the residual $\left(v_{r}\right)$ is measured.

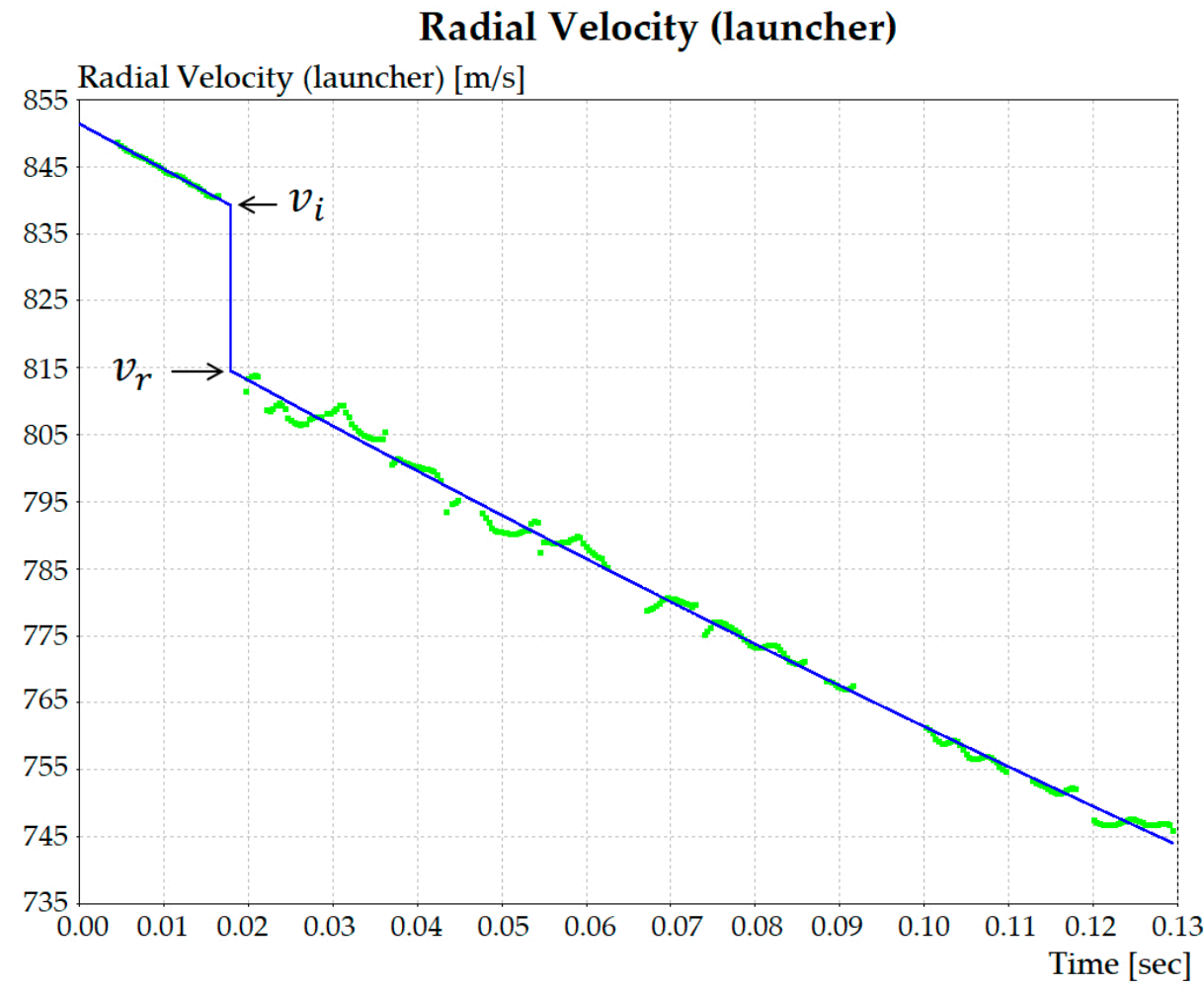

Figure 3. Experimental points obtained from the radar spectrum and the FFT curve fitting.

The other important parameter obtained from the stand-alone test is the limit velocity $\left(V_{L}\right)$ associated with the highest projectile velocity, which still did not perforate the target plate.

According to Morye et al. [23], the $V_{L}$ is a reference velocity that can be related to the maximum level of ammunition [16], which might verify the polymer composite target plate as an effective armor.

$$
V_{L}=\sqrt{\frac{2 \cdot E_{a b s}}{m_{p}}}
$$

\subsection{Weibull Statistical Analysis}

The absorbed energy values of seven samples for each different composite investigated in Table 1 were statistically treated using the Weibull method in terms of the cumulative distribution function. A logarithm-based linear expression [18] allows the graphical interpretation of the Weibull parameters:

$$
\ln \left[\ln \left(\frac{1}{1-F(x)}\right)\right]=\beta \cdot \ln (x)-[\beta \cdot \ln (\theta)]
$$

where $x$ is the absorbed energy, $\beta$ is the Weibull modulus and $\theta$ is the characteristic energy. 


\subsection{Analysis of Variance (ANOVA)}

In order to statistically compare average/standard deviation values of $E_{a b s}$ and $V_{L}$, ANOVA was applied to results obtained from the stand-alone ballistic test. The $5 \%$ significance level was adopted to verify whether there was a significant difference between the data. A calculated $\mathrm{F}_{\text {calc }}$ was compared with the tabulated critical $\mathrm{F}_{\text {crit }}$. In cases where $F_{\text {calc }}>F_{\text {crit }}$, i.e., $p$-value less than $0.05(5 \%)$, one could conclude with $95 \%$ confidence that there is a difference between the experimentally obtained average values. Otherwise, no difference exists if $\mathrm{F}_{\text {calc }}<\mathrm{F}_{\text {crit }}$.

\subsection{Scanning Electron Microscopy (SEM)}

SEM images of the fique fabric reinforced epoxy composites after the stand-alone ballistic tests were obtained in a model Quanta FEG 250 FEI microscope operating with secondary electrons at $15 \mathrm{kV}$. Ballistically fractured composite samples were gold-sputtered for electrical conductivity before SEM analysis.

\section{Results and Discussion}

\subsection{Stand-Alone Ballistic Tests}

Figure 4 shows the result of a typical stand-alone ballistic test using a $7.62 \mathrm{~mm}$ projectile against the fique fabric reinforced epoxy composites. A round metallic block, with a central circular hole with a diameter of $50 \mathrm{~mm}$, was clamped to the back of the target plate to direction the projectile by means of a laser beam (shown in Figure 4a). After the ballistic test, the projectile perforation at the center of the plate (Figure $4 \mathrm{~b}$ ) was revealed as a small dark orifice.
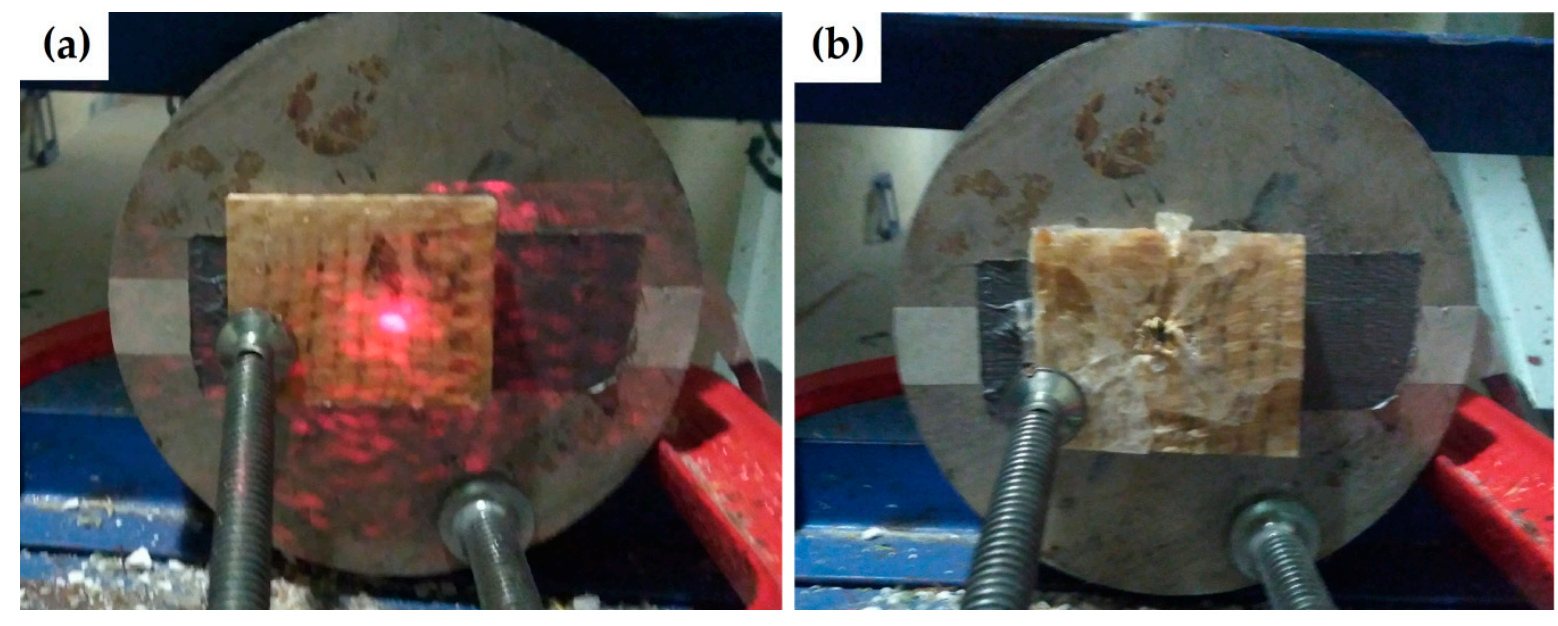

Figure 4. Typical stand-alone ballistic test: (a) before shooting, laser beam indicates the direction of $7.62 \mathrm{~mm}$ projectile with target plate clamped to a round metallic block; and (b) after shooting, there is perforated hole at the center of the plate.

Table 2 presents the main results from the stand-alone ballistic tests, including the determined impact, $v_{i}$, and residual, $v_{r}$, velocities, as well as the absorbed energy, $E_{a b s}$, calculated from Equation (1) [9], and the limit velocity, $V_{L}$, from Equation (2) [23]. In this table, not only are the results for the fique fabric reinforced epoxy composites reported, but previous results of the plain epoxy and the Kevlar ${ }^{\mathrm{TM}}$ stand-alone plates with the same $10 \mathrm{~mm}$ thickness $[11,24]$ are also shown. 
Table 2. Results of computer-recorded velocities and calculated parameters from $7.62 \mathrm{~mm}$ ballistic stand-alone tests for fique fabric reinforced epoxy composites, as well as previously reported results for plain epoxy and Kevlar ${ }^{\mathrm{TM}}$.

\begin{tabular}{|c|c|c|c|c|c|}
\hline $\begin{array}{c}\text { Stand-Alone } \\
10 \mathrm{~mm} \text { Thick Plate Target }\end{array}$ & $\begin{array}{c}v_{i} \\
(\mathrm{~m} / \mathrm{s})\end{array}$ & $\begin{array}{c}v_{r} \\
(\mathrm{~m} / \mathrm{s})\end{array}$ & $\begin{array}{c}E_{a b s} \\
(\mathrm{~J})\end{array}$ & $\begin{array}{c}V_{L} \\
(\mathrm{~m} / \mathrm{s})\end{array}$ & Ref. \\
\hline EC15FF & $839 \pm 7$ & $814 \pm 6$ & $203 \pm 26$ & $204 \pm 13$ & PW \\
\hline EC30FF & $840 \pm 8$ & $813 \pm 8$ & $209 \pm 55$ & $206 \pm 25$ & PW \\
\hline EC40FF & $837 \pm 4$ & $812 \pm 10$ & $200 \pm 56$ & $202 \pm 28$ & PW \\
\hline EC50FF & $843 \pm 4$ & $816 \pm 5$ & $219 \pm 59$ & $211 \pm 27$ & PW \\
\hline DGEBA/TETA epoxy & $850 \pm 2$ & $827 \pm 6$ & $190 \pm 61$ & $196 \pm 32$ & [11] \\
\hline Kevlar (ply of aramid fabric) & $848 \pm 6$ & $841 \pm 7$ & $58 \pm 29$ & $109 \pm 7$ & [24] \\
\hline
\end{tabular}

PW: Present work.

Figure 5 shows the Weibull graphs of absorbed energy for the investigated epoxy composites. In these graphs, reasonable linear plots indicate the similar energy absorption mechanisms for each composite. The corresponding mechanisms will be further discussed.
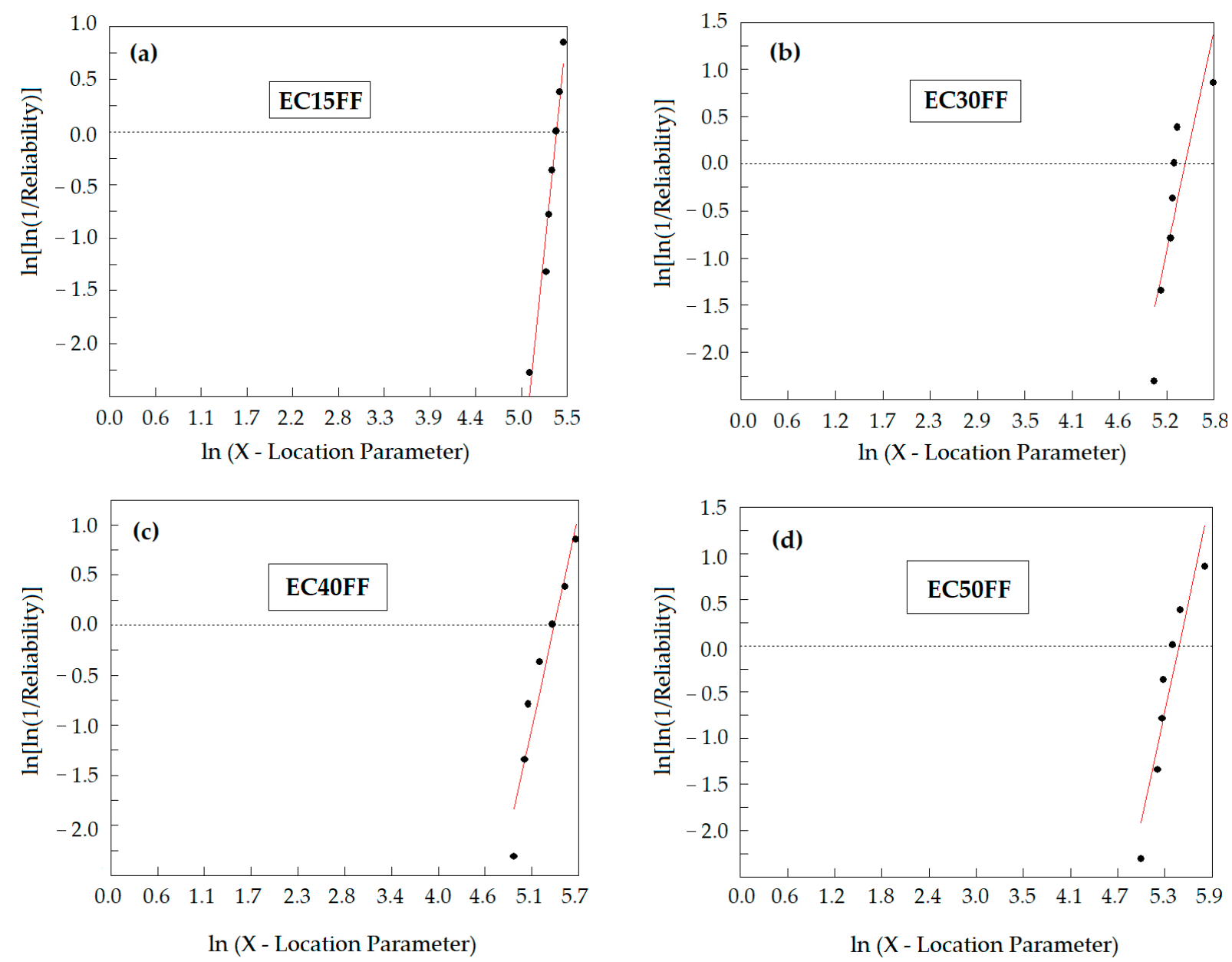

Figure 5. Weibull graphs of the stand-alone absorbed ballistic energy $\left(E_{a b s} \equiv x\right)$ for the investigated epoxy composites with: (a) $15 \mathrm{vol} \%$; (b) $30 \mathrm{vol} \%$; (c) $40 \mathrm{vol} \%$; and (d) $50 \mathrm{vol} \%$ fique fabric. Table 3.

The Weibull parameters calculated from the linear plots in Figure 5 are presented in 
Table 3. Weibull parameters related to stand-alone absorbed ballistic energy of fique fabric reinforced epoxy composites associated with graphs in Figure 5.

\begin{tabular}{cccc}
\hline $\begin{array}{c}\text { Stand-Alone } \\
\text { Composite Plate Target }\end{array}$ & $\boldsymbol{\beta}$ & $\boldsymbol{\theta}$ & $\mathbf{R}^{\mathbf{2}}$ \\
\hline EC15FF & 7.85 & 214.6 & 0.96 \\
EC30FF & 4.01 & 231.8 & 0.73 \\
EC40FF & 3.78 & 221.7 & 0.93 \\
EC50FF & 4.05 & 241.2 & 0.88 \\
\hline
\end{tabular}

In this table the relatively good precision of data is indicated by the values of $R^{2}$. However, the relatively low values of the Weibull modulus $\beta$ casts doubts on the possible similar energy absorption mechanisms for all the stand-alone tests of the plates with the same volume fraction of fique fabric. This will be further discussed.

Figure 6 shows the graphic variation of $E_{a b s}$ values presented in Table 2 as a function of the fique fabric volume fraction in the epoxy composites. This figure also discloses the value reported for the plain DGEBA/TETA stand-alone epoxy plate with the same $10 \mathrm{~mm}$ thickness [11]. The $E_{a b s}$ vs. vol\% graph in Figure 6 and bar corresponding to the $E_{a b s}$ value reported [24] for the Kevlar ${ }^{\mathrm{TM}}$ stand-alone plate with the same $10 \mathrm{~mm}$ thickness is also shown for comparison.

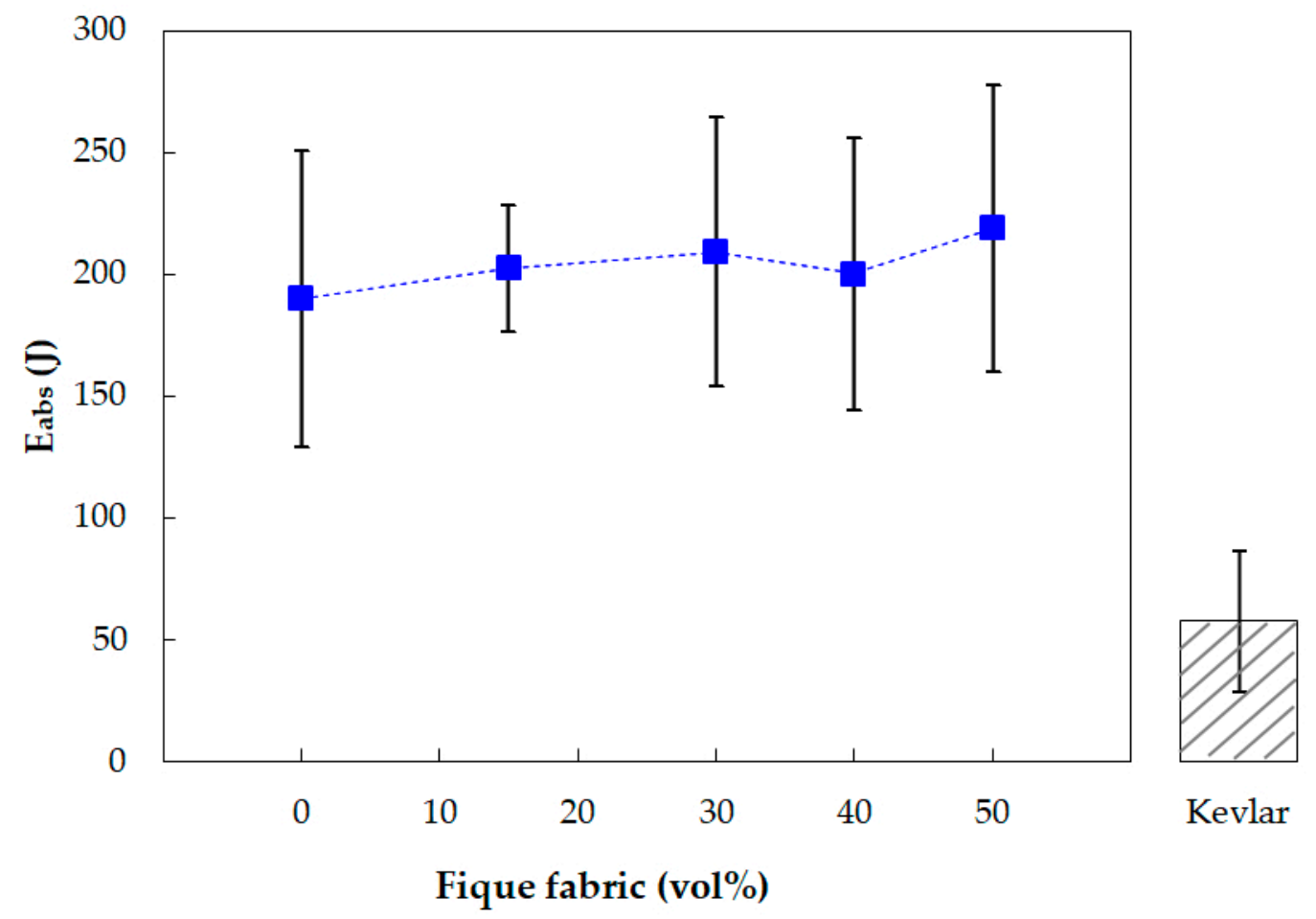

Figure 6. Variation of $E_{a b s}$ from the stand-alone test with the volume fraction (vol\%) of fique fabric. Reported $E_{a b s}$ value for Kevlar $^{\mathrm{TM}}$ indicated in adjacent bar [24].

Within the standard deviations in Figure 6, it is clearly seen that all composites, including the plain epoxy target, have the same $E_{a b s}$ values, whereas Kevlar ${ }^{\mathrm{TM}}$ has a much lower value.

\subsection{Analysis of Variance (ANOVA) for Absorbed Energy}

Table 4 presents the ANOVA for the $E_{a b s}$ obtained in the stand-alone ballistic tests of the fique fabric reinforced epoxy composites shown in Table 2 and Figure 6. In this table, it should be noted that $\mathrm{F}_{\text {calc }}<\mathrm{F}_{\text {crit }}$, which guarantees a $95 \%$ level of confidence that not only the values (200-219 J) for the investigated composites, but also that (190 J) of the 
previously reported $E_{a b s}$ of the plain epoxy [11], are statistically similar. The reported $E_{a b s}$ values within their standard deviation are significantly higher than those reported (58 J) for Kevlar ${ }^{\mathrm{TM}}$ [24], shown in the adjacent bar in Figure 6. One may then infer that the plain epoxy and the fique fabric composites more efficiently dissipate the $7.62 \mathrm{~mm}$ projectile impact energy as a stand-alone target plate, rather than Kevlar ${ }^{\mathrm{TM}}$ with the same thickness. The reason for this favorable ballistic behavior will be further discussed in association with the SEM fracture analysis.

Table 4. ANOVA of $E_{a b s}$ in the stand-alone ballistic test of fique fabric reinforced epoxy composites and plain epoxy.

\begin{tabular}{ccccccc}
\hline $\begin{array}{c}\text { Variation } \\
\text { Causes }\end{array}$ & $\begin{array}{c}\text { Sum of } \\
\text { Squares }\end{array}$ & DF & $\begin{array}{c}\text { Mean of } \\
\text { Squares }\end{array}$ & $\mathbf{F}_{\text {calc }}$ & $\mathbf{F}_{\text {crit }}$ & $p$-Value \\
\hline Treatment & 2304.48 & 4 & 576.12 & 0.22 & 2.74 & 0.93 \\
Residual & $69,215.74$ & 26 & 2662.14 & & & \\
Total & $71,520.22$ & 30 & & & & \\
\hline
\end{tabular}

\subsection{Limit Velocity Discussion}

In principle, the discussion on the calculated results for the limit velocity $\left(V_{L}\right)$ follows the same methodological reasoning presented in Section 3.1 for the absorbed energy $\left(E_{a b s}\right)$. In fact, it can be seen in Equation (2) that $V_{L}$ is found by a simple square root mathematical transformation of $E_{a b s}$. However, a comparison might still be interesting to perform between the $V_{L}$ values in Table 2 and those calculated from the Weibull characteristic energy $(\theta)$ in Table 3.

Figure 7 shows the variation of $V_{L}$ values presented in Table 2 as a function of fique fabric, including the value previously reported [11] for the plain epoxy. In this figure, the values of $V_{L}$ are also located with open circles which have been calculated with Equation (2) from the Weibull characteristic absorbed energy presented in Table 3.

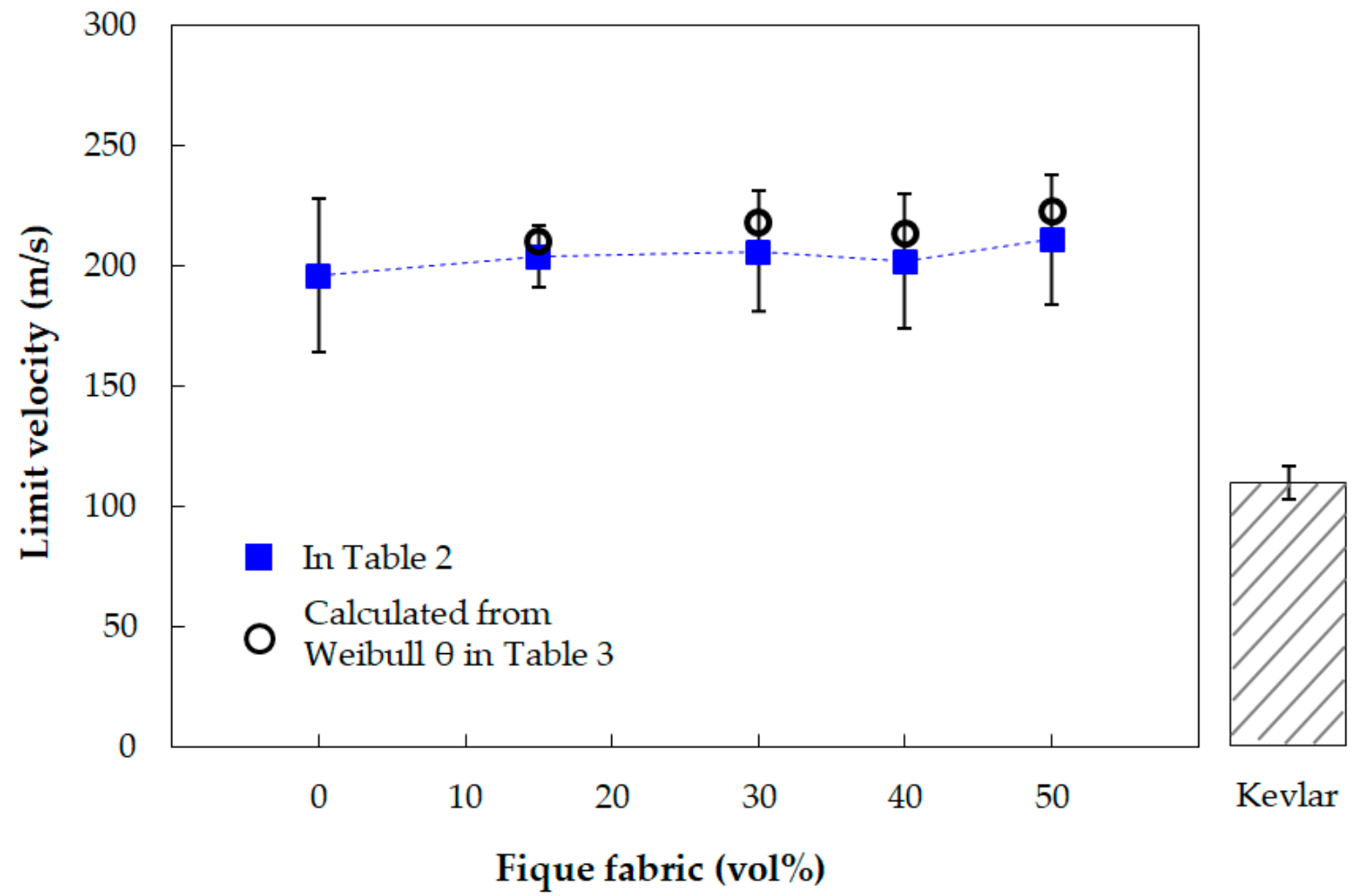

Figure 7. Variation of $V_{L}$ with the volume fraction of fique fabric from values in Table 2 and calculated from Weibull $\theta$ in Table 3. Reported $V_{L}$ value for Kevlar ${ }^{\mathrm{TM}}$ indicated in adjacent bar [24]. 
The graphical results shown in Figure 7 clearly demonstrate that $V_{L}$ remains constant, within 196-223 m/s, with an addition of up to $50 \mathrm{vol} \%$ of fique fabric in DGEBA/TETA

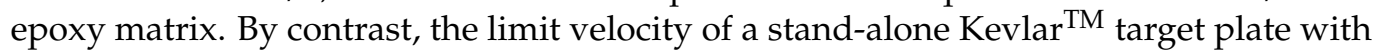
the same $10 \mathrm{~mm}$ thickness is significantly lower, $109 \pm 7 \mathrm{~m} / \mathrm{s}$ [24]. As mentioned, $V_{L}$ is associated with the highest projectile velocity for which the target plate with a given thickness is not perforated. As such, $V_{L}$ obtained for a given level of ammunition (in the present case a $7.62 \mathrm{~mm}$ rifle bullet) serves as an armor design reference. Table 5 compares the limit velocity obtained for the present investigated composites with those reported for epoxy composites incorporated with piassava [25] and mallow [26] natural fibers.

Table 5. Limit velocity for the fique fabric epoxy composites compared to piassava and mallow fiber epoxy composites.

\begin{tabular}{ccc}
\hline Epoxy Composite & $\begin{array}{c}\boldsymbol{V}_{\boldsymbol{L}} \\
(\mathbf{m} / \mathbf{s})\end{array}$ & Reference \\
\hline 15 vol\% fique fabric & $204 \pm 13$ & $\mathrm{PW}$ \\
30 vol\% fique fabric & $206 \pm 25$ & $\mathrm{PW}$ \\
40 vol\% fique fabric & $202 \pm 28$ & $\mathrm{PW}$ \\
50 vol\% fique fabric & $211 \pm 27$ & $\mathrm{PW}$ \\
10 vol\% piassava fiber & $236 \pm 8$ & {$[25]$} \\
20 vol\% piassava fiber & $200 \pm 9$ & {$[25]$} \\
30 vol\% piassava fiber & $202 \pm 7$ & {$[25]$} \\
40 vol\% piassava fiber & $198 \pm 6$ & {$[25]$} \\
50 vol\% piassava fiber & $204 \pm 2$ & {$[25]$} \\
30 vol\% mallow fiber & $231 \pm 18$ & {$[26]$} \\
\hline
\end{tabular}

PW: Present work.

All results in Table 5, obtained in similar ballistic tests using $7.62 \mathrm{~mm}$ ammunition, display comparable values.

In principle, the results of Figure 7 indicate that against the threat of $7.62 \mathrm{~mm}$ ammunition, an armor of epoxy reinforced with up to $50 \mathrm{vol} \%$ fique fabric could be designed with half the thickness of a Kevlar ${ }^{\mathrm{TM}}$ plate. This represents cost and weight reductions as practical advantages. In terms of cost, Oliveira et al. [18] reported that a $150 \times 150 \mathrm{~mm}^{2}$ ballistic plate with a $10 \mathrm{~mm}$ of thickness made of epoxy composite, incorporated with $40 \mathrm{vol} \%$ of fique fabric, would cost USD 3.67, whereas the same plate made of Kevlar ${ }^{\mathrm{TM}}$ would cost USD 20.61. These findings present the same plate made of Kevlar ${ }^{\mathrm{TM}}$ as more than five times the price of the fique fabric composite. In addition, there are environmental and societal benefits associated with the use of natural fiber and fabrics [27]. However, integrity is another point to be considered in armor design [16].

It was previously found [11] that a plain epoxy is associated with a relatively high limit velocity (196 m/s in Table 2) but was found to completely shatter after the impact of a $7.62 \mathrm{~mm}$ projectile. In comparison, a stand-alone Kevlar ${ }^{\mathrm{TM}}$ plate kept its integrity [24]. Regarding the investigated fique fabric composites, the question remains as to whether they withhold the necessary integrity to withstand subsequent shooting as required by the standards.

\subsection{Composites Integrity and Failure Analyses}

Figure 8 illustrates the typical fique fabric epoxy composite stand-alone plates after the ballistic test. Composites with $15 \mathrm{vol} \%$ (Figure $8 \mathrm{a}$ ) and $30 \mathrm{vol} \%$ (Figure $8 \mathrm{~b}$ ) of fique fabric display visible damages in the form of macrocracks. Similar to the shattered plain epoxy, these composites with 15 and $30 \mathrm{vol} \%$ of fique fabric are ruled out as possible armor, even with the thickness large enough to be associated with a limit velocity of $\sim 840 \mathrm{~m} / \mathrm{s}$, corresponding to a $7.62 \mathrm{~mm}$ projectile. On the other hand, composites with $40 \mathrm{vol} \%$ (Figure $8 \mathrm{c}$ ) and $50 \mathrm{vol} \%$ (Figure $8 \mathrm{~d}$ ) did not develop macrocracks, and might withstand subsequent shootings without open spaces that allow the easy passage of the projectile. All of the composites in Figure 8 show a central hole from where the projectile 
perforated the target plate. Figure 8 also presents the plain epoxy plate completely fractured after the ballistic impact in the stand-alone test (Figure 8e).
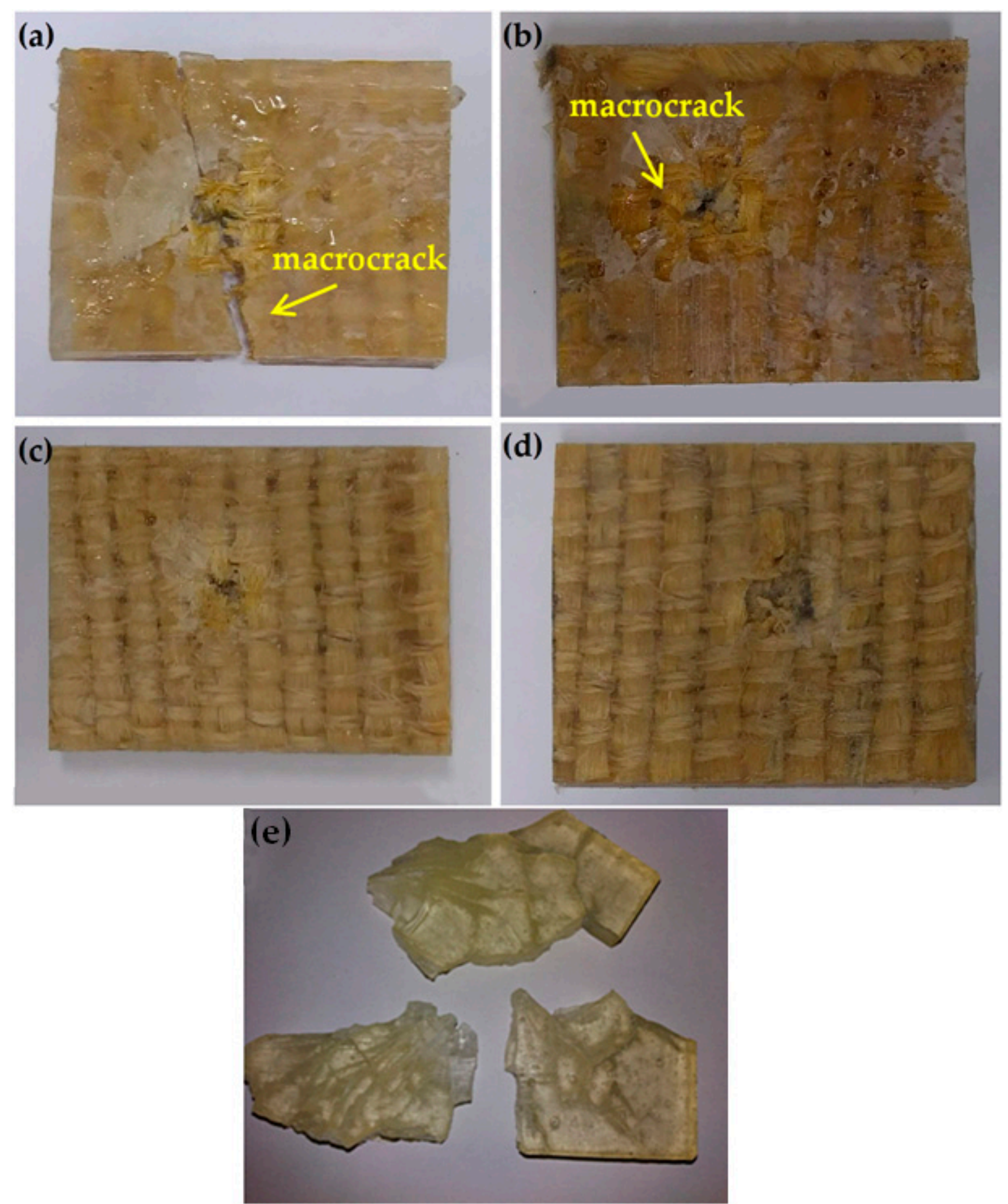

Figure 8. Stand-alone epoxy composite plates after the ballistic test against $7.62 \mathrm{~mm}$ ammunition: (a) $15 \mathrm{vol} \%$; (b) $30 \mathrm{vol} \%$; (c) $40 \mathrm{vol} \%$; (d) $50 \mathrm{vol} \%$ fique fabric; and (e) plain epoxy plate.

As shown in Figure 8, both of the 15 and 30 vol\% fabric epoxy composites display damage by macrocracks that hinder their application as ballistic armor. The SEM observation with the high magnification of a macrocrack in the epoxy composite with $15 \mathrm{vol} \%$ of fique fabric is shown in Figure 9a. In this figure, a clear separation exists between fibers in the fique fabric and the epoxy matrix. This separation on a large scale constitutes evidence 
of delamination, which could be associated with the main damage caused to the composite structure by the $7.62 \mathrm{~mm}$ projectile impact. Another consequence of this impact is the fique fiber rupture causing microfibrillation, illustrated in the inset of Figure 9b. On the other hand, the SEM analysis of the damaged regions close to the bullet penetration hole in the $40 \mathrm{vol} \%$ fique fabric composite in Figure $9 \mathrm{c}$ showed only microcracks and broken fibers. No evidence of lamination could be found in this composite with a higher volume fraction of fique fabric. These different mechanisms occurring in the fique fabric composites might justify the relatively low values of the Weibull moduli in Table 3.
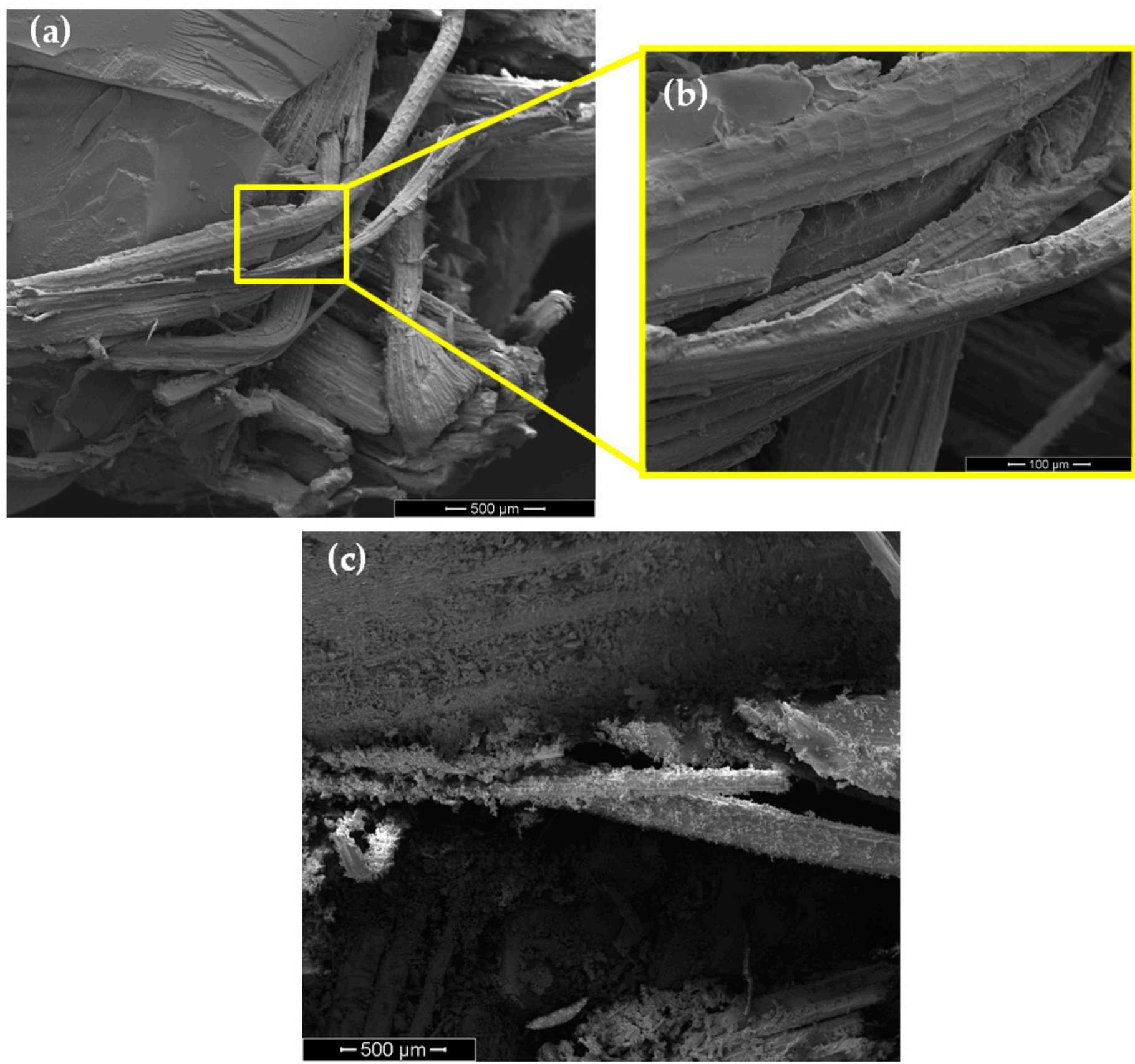

Figure 9. SEM image of the damage in the epoxy composite with $15 \mathrm{vol} \%$ of fique fabric (a,b); and with $40 \mathrm{vol} \%$ of fique fabric (c).

With the exception of the central perforated hole (Figure $8 \mathrm{c}, \mathrm{d}$ ), no apparent visible damage occurred for the 40 and $50 \mathrm{vol} \%$ fique fabric composites. One may infer that volume fractions above $30 \mathrm{vol} \%$ fique fabric composites prevent delamination and maintain 
the composite integrity, which is required for protection against subsequent shooting [16]. Therefore, this brief report complements the previous work [18] in which the same fique fabric reinforced epoxy composites were found to provide effective protection as an MAS second layer against $7.62 \mathrm{~mm}$ ammunition. Herein, however, it is revealed that, as standalone armor, only epoxy composites with an amount of fique fabric above $30 \mathrm{vol} \%$ will guarantee effective ballistic protection. These composites were also found to have superior ballistic performance in terms of absorbing impact energy and limiting velocity, as compared to a Kevlar ${ }^{\mathrm{TM}}$ armor plate with the same thickness.

\section{Summary and Conclusions}

The plain woven fabric made of fique fibers, extracted from the leaves of Furcraea andina, was used in amounts of 15, 30, 40 and $50 \mathrm{vol} \%$ of epoxy matrix composite reinforcement and ballistic-tested as a stand-alone target plate with $10 \mathrm{~mm}$ thickness against $7.62 \mathrm{~mm}$ rifle ammunition.

The absorbed impact energy $\left(E_{a b s}\right)$ of 200-219 J, including the already reported value of $190 \mathrm{~J}$ for the plain epoxy, are found to be equal by the ANOVA test with a $95 \%$ level of confidence. These values are significantly higher than the $E_{a b s}$ of $58 \mathrm{~J}$ reported for the aramid fabric $\left(\operatorname{Kevlar}^{\mathrm{TM}}\right)$ target plate with the same thickness.

The limit velocity $\left(V_{L}\right)$ calculated from both the absorbed impact energy $(202-211 \mathrm{~m} / \mathrm{s})$ and the Weibull characteristic parameter $(210-223 \mathrm{~m} / \mathrm{s})$, including the previously reported value of $196 \mathrm{~m} / \mathrm{s}$ for the plain epoxy, are practically similar within the standard deviations. On the contrary, the $V_{L}$ reported for the Kevlar ${ }^{\mathrm{TM}} 10 \mathrm{~mm}$ thick stand-alone target plate of $109 \mathrm{~m} / \mathrm{s}$ is marked lower.

The visible macrocracks developed in the 15 and $30 \mathrm{vol} \%$ fique fabric composites compromise their application as $10 \mathrm{~mm}$ thick armor plates. In the case of the plain epoxy, the plate was reported to be completely shattered. As for the 40 and $50 \mathrm{vol} \%$, only the projectile perforation hole was visible, which indicated that the integrity was maintained.

The SEM analysis revealed that the main damage responsible for the macrocracks is associated with fiber/matrix delamination and fiber rupture causing microfibrillation.

As stand-alone armor, only epoxy composites reinforced with more than $30 \mathrm{vol} \%$ of fique fabric guarantee superior ballistic protection compared to Kevlar ${ }^{\mathrm{TM}}$.

The present ballistic results disclose an optimistic prospective for future research on natural fabric polymer composites as a possible substitute for more expensive and currently used synthetic laminates in personal armor protection.

Author Contributions: Conceptualization, data curation, investigation, methodology, M.S.O.; investigation, formal analysis, writing - original draft, and writing-review and editing, F.S.d.L.; conceptualization, visualization, and funding acquisition, H.A.C.L.; conceptualization, data curation, and visualization, L.F.C.N.; conceptualization, data curation, and visualization, F.d.C.G.F.; validation, funding acquisition, project administration, and writing-review and editing, S.N.M. All authors have read and agreed to the published version of the manuscript.

Funding: This research was partially financed by the Coordination for the Improvement of Higher Education Personnel (CAPES), Brazil-Finance Code 001, Carlos Chagas Filho Foundation for Research Support of the State of Rio de Janeiro (FAPERJ) process E-26/202.286/2018, and the Brazilian National Council of Scientific Technological and Innovation Development (CNPq) grant number 423462/2018-0.

Acknowledgments: The authors would like to thank the Brazilian agencies CNPq, CAPES and FAPERJ (process E-26/202.286/2018) for their support.

Conflicts of Interest: The authors declare no conflict of interest.

\section{References}

1. Lee, Y.S.; Wetzel, E.D.; Wagner, N.J. The Ballistic Impact Characteristic of kevlar woven fabrics impregnated with a colloidal shear thickening fluid. J. Mater. Sci. 2003, 38, 2825-2833. [CrossRef] 
2. Monteiro, S.N.; Lima, E.P., Jr.; Louro, L.H.L.; Silva, L.C.; Drelich, J.W. Unlocking function of aramid fibers in multilayered ballistic armor. Mettal. Mat. Trans. A 2014, 46,37-40. [CrossRef]

3. Luz, F.S.; Garcia Filho, F.C.; Oliveira, M.S.; Nascimento, L.F.C.; Monteiro, S.N. Composites with natural fibers and conventional materials applied in a hard armor: A comparison. Polymers 2020, 12, 1920. [CrossRef]

4. Benzait, Z.; Trabzon, L. A review of recent research on materials used in polymer-matrix composites for body armor application J. Compos. Mater. 2018, 52, 3241-3263. [CrossRef]

5. Nayak, S.Y.; Sultan, M.T.H.; Shenoy, S.B.; Kini, C.R.; Samant, R.; Shah, A.U.M.; Amuthakkannan, P. Potential of natural fibers in composites for ballistic applications-A review. J. Nat. Fibers 2021, 44, 1-11. [CrossRef]

6. Nurazzi, N.M.; Asyraf, M.R.M.; Khalina, A.; Abdullah, N.; Aisyah, H.A.; Rafiqah, S.; Sabaruddin, F.A.; Kamarudin, S.H.; Norrrahim, M.N.F.; Ilyas, A.; et al. A review on natural fiber reinforced polymer composite for bullet proof and ballistic applications. Polymers 2021, 13, 646. [CrossRef]

7. Odesanya, K.O.; Ahmad, R.; Jawaid, M.; Bingol, S.; Adebayo, G.O.; Wong, Y.H. Natural fibre-reinforced composite for ballistic applications: A review. J. Polym. Environ. 2021, 10, 1-18. [CrossRef]

8. Monteiro, S.N.; Milanezi, T.L.; Louro, L.H.L.; Lima Jr, E.P.; Braga, F.O.; Gomes, A.V.; Drelich, J.W. Novel ballistic ramie fabric composite competing with Kevlar ${ }^{\mathrm{TM}}$ fabric in multilayered armor. Mater. Des. 2016, 96, 263-269. [CrossRef]

9. Oliveira, M.S.; Luz, F.S.; Teixeira Souza, A.; Demosthenes, L.C.C.; Pereira, A.C.; Filho, F.C.G.; Braga, F.O.; Figueiredo, A.B.H.S.; Monteiro, S.N. Tucum Fiber from Amazon Astrocaryum vulgare Palm Tree: Novel Reinforcement for Polymer Composites. Polymers 2020, 12, 2259. [CrossRef] [PubMed]

10. Ribeiro, M.P.; Neuba, L.M.; da Silveira, P.H.P.M.; da Luz, F.S.; da Silva Figueiredo, A.B.H.; Monteiro, S.N.; Moreira, M.O. Mechanical, thermal and ballistic performance of epoxy composites reinforced with Cannabis sativa hemp fabric. J. Mater. Res. Technol. 2021, 12, 221-233. [CrossRef]

11. Monteiro, S.N.; Louro, L.H.L.; Trindade, W.; Elias, C.N.; Ferreira, C.L.; de Sousa Lima, E.; Weber, R.P.; Suarez, J.C.; Figueiredo, A.B.H.S.; Pinheiro, W.A.; et al. Natural curaua fiber-reinforced composites in multilayered ballistic armor. Metall. Mater. Trans. A 2015, 46, 4567-4577. [CrossRef]

12. Luz, F.S.; Garcia Filho, F.C.; del-Río, M.T.G.; Nascimento, L.F.C.; Pinheiro, W.A.; Monteiro, S.N. Graphene-Incorporated Natural Fiber Polymer Composites: A First Overview. Polymers 2020, 12, 1601. [CrossRef]

13. Garcia Filho, F.C.; Luz, F.S.; Oliveira, M.S.; Bezerra, W.B.A.; Barbosa, J.D.V.; Monteiro, S.N. Influence of Rigid Brazilian Natural Fiber Arrangements in Polymer Composites: Energy Absorption and Ballistic Efficiency. J. Compos. Sci. 2021, 5, 201. [CrossRef]

14. Reis, R.H.M.; Nunes, L.F.; da Luz, F.S.; Candido, V.S.; da Silva, A.C.R.; Monteiro, S.N. Ballistic Performance of Guaruman Fiber Composites in Multilayered Armor System and as Single Target. Polymers 2021, 13, 1203. [CrossRef] [PubMed]

15. Monteiro, S.N.; Drelich, J.W.; Lopera, H.A.C.; Nascimento, L.F.C.; da Luz, F.S.; da Silva, L.C. Natural Fibers Reinforced Polymer Composites Applied in Ballistic Multilayered Armor for Personal Protection-An overview. In Green Materials Engineering; The Minerals, Metals \& Materials Series; Ikhmayies, S., Li, J., Vieira, C., Margem Deceased, J., de Oliveira Braga, F., Eds.; Springer: Cham, Switzerland, 2019; pp. 33-47. [CrossRef]

16. National Criminal Justice Reference Service. US Department of Justice, \& National Institute of Justice. NIJ 0101.06. Ballistic Resistance of Body Armor. 2008. Available online: https:/ /nij.ojp.gov/library/publications/ballistic-resistance-body-armor-nijstandard-010106 (accessed on 5 July 2021).

17. Pereira, A.C.; de Assis, F.S.; Garcia Filho, F.C.; Oliveira, M.S.; Demosthenes, L.C.C.; Lopera, H.A.C.; Monteiro, S.N. Ballistic performance of multilayered armor with intermediate polyester composite reinforced with fique natural fabric and fibers. $J$. Mater. Res. Technol. 2019, 8, 4221-4226. [CrossRef]

18. Oliveira, M.S.; Garcia Filho, F.C.; Pereira, A.C.; Nunes, L.F.; da Luz, F.S.; Braga, F.O.; Colorado, H.A.; Monteiro, S.N. Ballistic performance and statistical evaluation of multilayered armor with epoxy-fique fabric composites using the Weibull analysis. $J$. Mater. Res. Technol. 2019, 8, 5899-5908. [CrossRef]

19. Oliveira, M.S.; Garcia Filho, F.C.; Luz, F.S.; Pereira, A.C.; Demosthenes, L.C.C.; Nascimento, L.F.C.; Lopera, H.A.C.; Monteiro, S.N. Statistical analysis of notch toughness of epoxy matrix composites reinforced with fique fabric. J. Mater. Res. Technol. 2019, 8 , 6051-6057. [CrossRef]

20. Oliveira, M.S.; Garcia Filho, F.C.; Luz, F.S.; Pereira, A.C.; Demosthenes, L.C.C.; Nascimento, L.F.C.; Monteiro, S.N. Tensile Properties of Epoxy Matrix Reinforced with Fique Fabric. MSF 2020, 1012, 14-19. [CrossRef]

21. Brazilian Association of Technical Norms, ABNT NBR 10591/2008. Textiles Materials—Determination of Mass per Unit Area; ABNT: São Paulo, Brazil, 2008.

22. Monteiro, S.N.; Assis, F.S.; Ferreira, C.L.; Simonassi, N.T.; Weber, R.P.; Oliveira, M.S.; Colorado, H.A.; Pereira, A.C. Fique Fabric: A Promising Reinforcement for Polymer Composites. Polymers 2018, 10, 246. [CrossRef]

23. Morye, S.S.; Hine, P.J.; Duckett, R.A.; Carr, D.J.; Ward, I.M. Modelling of the energy absorption by polymer composites upon ballistic impact. Compos. Sci. Technol. 2000, 60, 2631-2642. [CrossRef]

24. Luz, F.S.; Lima, E.P.; Louro, L.H.L.; Monteiro, S.N. Ballistic test of multilayered armor with intermediate epoxy composite reinforced with jute fabric. Mater. Res. 2015, 18, 170-177. [CrossRef]

25. Garcia Filho, F.D.C.; Oliveira, M.S.; Pereira, A.C.; Nascimento, L.F.C.; Matheus, J.R.G.; Monteiro, S.N. Ballistic behavior of epoxy matrix composites reinforced with piassava fiber against high energy ammunition. J. Mater. Res. Technol. 2020, 9, 1734-1741. [CrossRef] 
26. Nascimento, L.F.C.; Louro, L.H.L.; Monteiro, S.N.; Lima, É.P.; Luz, F.S. Mallow fiber-reinforced epoxy composites in multilayered armor for personal ballistic protection. JOM 2017, 69, 2052-2056. [CrossRef]

27. Nascimento, L.F.C.; Louro, L.H.L.; Monteiro, S.N.; Braga, F.O.; da Luz, F.S.; dos Santos, J.L.; Marçal, R.L.S.B.; Freitas, H.C.O.; Lima Júnior, É.P. Limit Speed Analysis and Absorbed Energy in Multilayer Armor with Epoxy Composite Reinforced with Mallow Fibers and Mallow and Jute Hybrid Fabric. In Characterization of Minerals, Metals, and Materials 2018; The Minerals, Metals \& Materials Series; Li, B., Ed.; Springer: Cham, Switzerland, 2018; pp. 597-604. [CrossRef] 